\title{
The Study of Effective of Added Aluminum Oxide Nano Particles to the Drilling Fluid: The Evaluation of Two Synthesis Methods
}

\section{Sajjad Hosseini ${ }^{1}$, Farshad Farahbod ${ }^{2 *}$ and Ghassem Zargar $^{3}$}

${ }^{1}$ Department of Petroleum Engineering, Science and Research Branch, Islamic Azad University, Tehran, Iran

${ }^{2}$ Department of Chemical Engineering, Firoozabad Branch, Islamic Azad University, Firoozabad, Iran

${ }^{3}$ Department of Oil Engineering, Petroleum University of Technology, Ahwaz, Iran

\begin{abstract}
In this paper, the tests are designed for investigation of the effects of the synthesized $\mathrm{Al}_{2} \mathrm{O}_{3}$ nano particle prepared by ultrasonic and microwave on the drilling fluid flowing properties. Nano particles which are prepared with two different methods of ultrasonic and microwave are applied in drilling fluid. Experiments are held in heated tube section for simple drilling fluid and drilling fluid which contains $1 \%$ nano Aluminum oxide. Results illustrate on the numerical difference between values obtained from ultrasonic nano drilling fluid and those are obtained from microwave nano drilling fluid. Results show the addition of $1 \%$ nano aluminum oxide which is prepared by ultrasonic method into drilling fluid increases the amount of friction factor $6.84 \%$ and velocity about $4.4 \%$, averagely. Also, the addition of $1 \%$ nano aluminum oxide which is prepared by microwave method into drilling fluid increases the amount of friction factor $5.8 \%$ and velocity about $3.7 \%$, averagely.
\end{abstract}

Keywords: Rheology; Drilling fluid; Heat properties; Microwave; Ultra-sonic

\section{Introduction}

The rheology is defined as the science of deformation and flow of matter. As a theoretical subject, the rheology is a branch of physics and physical chemistry; commonly classified as a branch of fluid mechanics [1]. The rheology itself has been acknowledged as a separate scientific branch since the mid 1920's. All real materials will deform to some extent when subjected to stress. If the material is an ideal liquid it may" deform continuously" or flow when a force is applied. For ideal solids the deformation will be elastic [2]. The relationship between the applied force and the resulting deformation is a unique function of each specific material. For fluids, i.e., liquids and gases, this function is known as a rheological property of the material $[3,4]$. Fluids are classified by their rheological behavior American Petroleum Institute. All fluids are classified as either Newtonian or Non-Newtonian, the clearest distinction between different types of fluids.

\section{Fluid mechanics}

Fluid mechanics is the study of the forces involved in both still and flowing fluids.

\section{Flow regimes}

Flow in circular pipes can behave in different ways. Most common fluids are transported in circular pipes. This is because pipes can withstand a large difference in pressure between the inside and outside of the pipe, without being significantly distorted [5]. The theory behind fluid flow is commonly well understood, yet only fully developed laminar flow is theoretically obtained [6]. Therefore flow with other characteristics, like turbulent flow, must rely on experimental and empirical relations. The borderlines between laminar, transitional and turbulent flow regimes are set by the Reynolds number of the flow [7]. For laminar flow, the viscous forces dominate, while for turbulent flow the inertial forces play the bigger role American Petroleum Institute. All fluid flow inside a pipe has the velocity profile of zero at the pipe wall due to no-slip condition to a maximum at the center of the pipe
[8].

\section{Role of drilling fluid}

The drilling fluid plays an integral part of all drilling operations, and should be optimized according to different parameters to achieve the best results and industrial effectiveness [9]. The main tasks for the drilling fluids are: A. Hole cleaning, getting the crushed material out from the well. It is important that the hole is properly cleaned with regards to completing the well. B. Controlling formation pressure (being a barrier). C. Buoyancy. Keeping the drill string submersed reduces the effective weight of the drill string on the hook load. This also reduces fatigue and costs (need less high strength steel in the top of the drill string). D. Lubrication, smoothening operation for the bit and also the drill string in long deviated/horizontal wells. E. Cooling, keeping the drill bit cool, in order to keep change the mechanical properties of the bit. F. Provide power to the bit. Hydraulic power is transmitted so that the can cones rotate (Only valid for roller-cone bits) [10]. For PDC bits the hydraulic power is used for jetting the crushed rock away from the bit teeth. G. Keeping the wellbore stable with regards to chemical reactions $[11,12]$. Shale can be a problem. H. Signal transfer. For real time measurements and logging, the drilling fluid itself is used as the transfer medium for pressure waves. I. Costs. Drilling fluids are an expensive part of the operations, and should be handled with care to avoid excessive spending [13]. The physical properties of Nano drilling fluid as novel drilling fluid are evaluated in this paper.

"Corresponding author: Farshad Farahbod, Department of Chemica Engineering, Firoozabad Branch, Islamic Azad University, Firoozabad, Iran, E-mail:mf_fche@yahoo.com

Receive April 23, 2016; Accepted June 15, 2016; Published June 21, 2016

Citation: Hosseini S, Farahbod F, Zargar G (2016) The Study of Effective of Added Aluminum Oxide Nano Particles to the Drilling Fluid: The Evaluation of Two Synthesis Methods. J Pet Environ Biotechnol 7: 283. doi:10.4172/2157 7463.1000283

Copyright: (c) 2016 Hosseini S, et al. This is an open-access article distributed under the terms of the Creative Commons Attribution License, which permits unrestricted use, distribution, and reproduction in any medium, provided the original author and source are credited. 
Citation: Hosseini S, Farahbod F, Zargar G (2016) The Study of Effective of Added Aluminum Oxide Nano Particles to the Drilling Fluid: The Evaluation of Two Synthesis Methods. J Pet Environ Biotechnol 7: 283. doi:10.4172/2157-7463.1000283

\section{Materials and Methods}

\section{Composition of drilling fluid}

The composition of drilling fluid is classified according to the Table 1.

\section{Aluminium oxide nano particles}

Aluminium oxide nano particle is an environmental friendly element and has a huge variety of applications. Aluminum is available as essential mineral and is non-toxic in low concentration.

\section{Experimental set up}

The experimental set up includes mixing tank, adiabatic tube test section and electrical heater is used to survey the behavior of Nano drilling fluid with two types of ultrasound Nano and microwave Nano.

\section{Results and Discussion}

\section{Peclet number}

Figure 1 shows the amounts of Peclet number through the tube length. Peclet number shows the effect of Reynolds and Prandtl number, together. The decrease trend is shown through the tube for three types of drilling fluid according to the Figure 1. The decrease trend in amounts of Prandtl number can indicate this trend in amounts of Peclet number. Addition of Nano particle (1\%) shows a little bit higher values of Peclet number. The highest values of Peclet number are related to the Nano drilling fluid which is prepared by microwave method.

\section{Hydrodynamic properties}

Velocity changes through the tube are important in properties

\begin{tabular}{|c|c|}
\hline Component & Weight Percentage \\
\hline Water & 48.67 \\
\hline glycol & 2.38 \\
\hline Polyacrylamide & 17.37 \\
\hline Sodium bicarbonate & 3.6 \\
\hline Calcium carbonate & 9.2 \\
\hline NaCl & 16 \\
\hline Potassium chloride & 2.78 \\
\hline
\end{tabular}

Table 1: Composition of drilling fluid of drilling fluid. Figure 2 shows the values of velocity versus tube section. Figure 2 shows the average velocity in the pipe line. The values of velocity commonly decrease in tube because of friction and viscous dissipation. The changes in velocity through 0.3 meter of tube for simple drilling fluid without Nano particle are from $1.7 \mathrm{~m} / \mathrm{sec}$ to $1.53 \mathrm{~m} / \mathrm{sec}$. Addition of $1 \%$ Nano particle decreases the velocity loss through the tube. Ultrasonic method prepared Nano fluid changes the values of average velocity from $1.7 \mathrm{~m} / \mathrm{sec}$ to $1.68 \mathrm{~m} / \mathrm{sec}$. The changes in velocity using microwave method Nano fluid are from $1.7 \mathrm{~m} / \mathrm{sec}$ to $1.66 \mathrm{~m} / \mathrm{sec}$. So, ultrasonic Nano drilling fluid seems to present better hydrodynamic performance. This may relate to the lower viscosity of Nano drilling fluid. So, values of viscosities are measured below.

Figure 3 shows values of dynamic viscosity versus temperature. Dynamic viscosity is responsible of amount of viscous dissipation. Obviously, the increase in temperature values decreases values of fluid dynamic viscosity. This trend is obtained for Nano drilling fluid. Also, the lower values of dynamic viscosity are obtained using Nano drilling fluid. This may describe the lower changes in amounts of average velocity for Nano drilling fluid. Temperature changes from $25^{\circ} \mathrm{C}$ to $85^{\circ} \mathrm{C}$, changes the values of dynamic viscosity from $40 \mathrm{cp}$ to $25 \mathrm{cp}$ for simple drilling fluid. The same mentioned temperature changes causes the changes from $31 \mathrm{cp}$ to $18 \mathrm{cp}$ for ultrasonic prepared Nano drilling fluid $30 \mathrm{cp}$ to $14 \mathrm{cp}$ for microwave prepared Nano drilling fluid. The effect of temperature on the amount of cinematic viscosity is shown in Figure 4. The increase in temperature values decreases values of cinematic viscosity. Of course, the lower values of dynamic viscosity describe the lower values of cinematic viscosity.

Effective viscosity versus temperature is shown in Figure 5. The amounts of effective viscosity decrease with temperature increase from $30^{\circ} \mathrm{C}$ to $80^{\circ} \mathrm{C}$. Values of effective viscosity for drilling fluid without Nano changes from 51.2 to 7.7. The changes of effective viscosity for microwave Nano drilling fluid and for Ultrasonic Nano drilling fluid are from 41.12 to 2.12 and from 39.7 to 1.9 , respectively.

Figure 6 shows the values of yield point versus different temperatures. The increase in the amount of temperature from $30^{\circ} \mathrm{C}$ to $80^{\circ} \mathrm{C}$ decreases the amount of yield point from 18.7 to 13.05 for simple drilling fluid without Nano particle. Addition of Nano particle (1\%) by method of ultrasonic and microwave decreases the values of yield point from 13.8 to 10.03 and from 12 to 5.9 , respectively. Amounts of yield point indicate on the ability of drilling mud to carry rocks out of well.

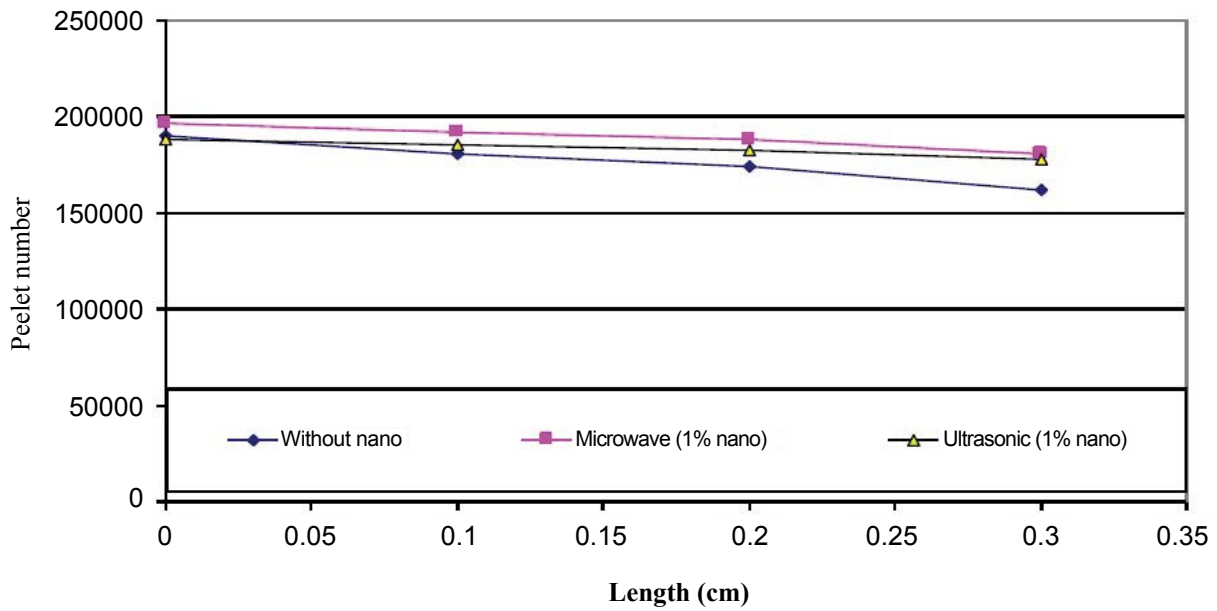

Figure 1: Peclet number versus length. 
Citation: Hosseini S, Farahbod F, Zargar G (2016) The Study of Effective of Added Aluminum Oxide Nano Particles to the Drilling Fluid: The Evaluation of Two Synthesis Methods. J Pet Environ Biotechnol 7: 283. doi:10.4172/2157-7463.1000283

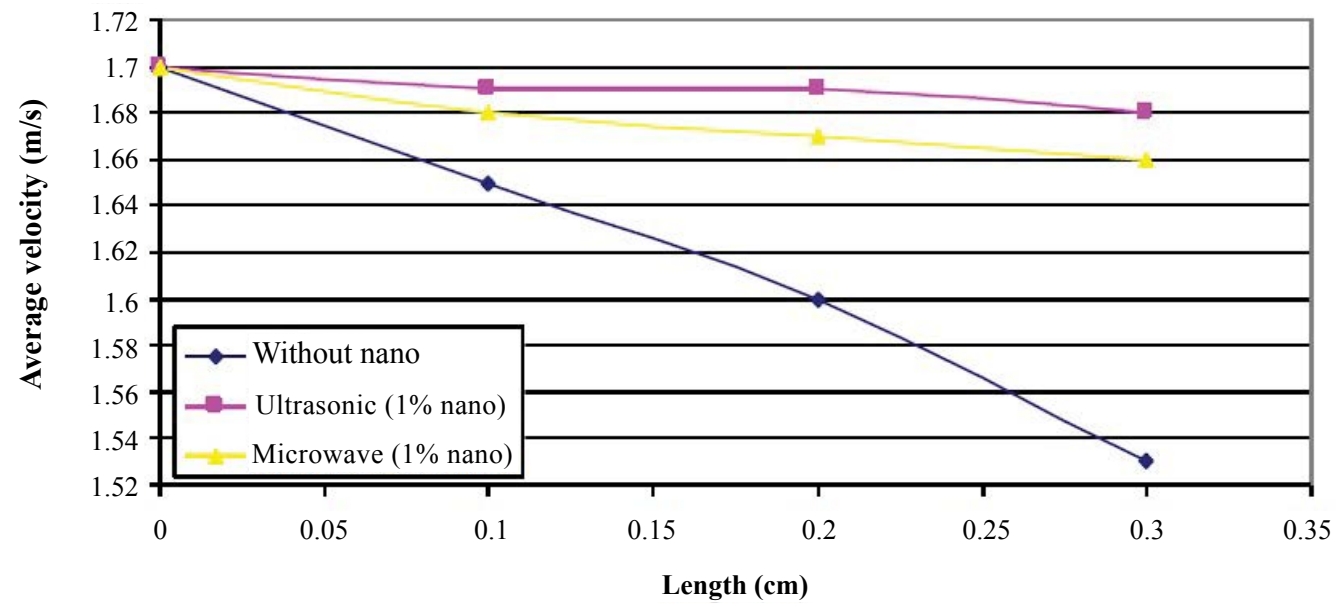

Figure 2: Average velocity versus length.

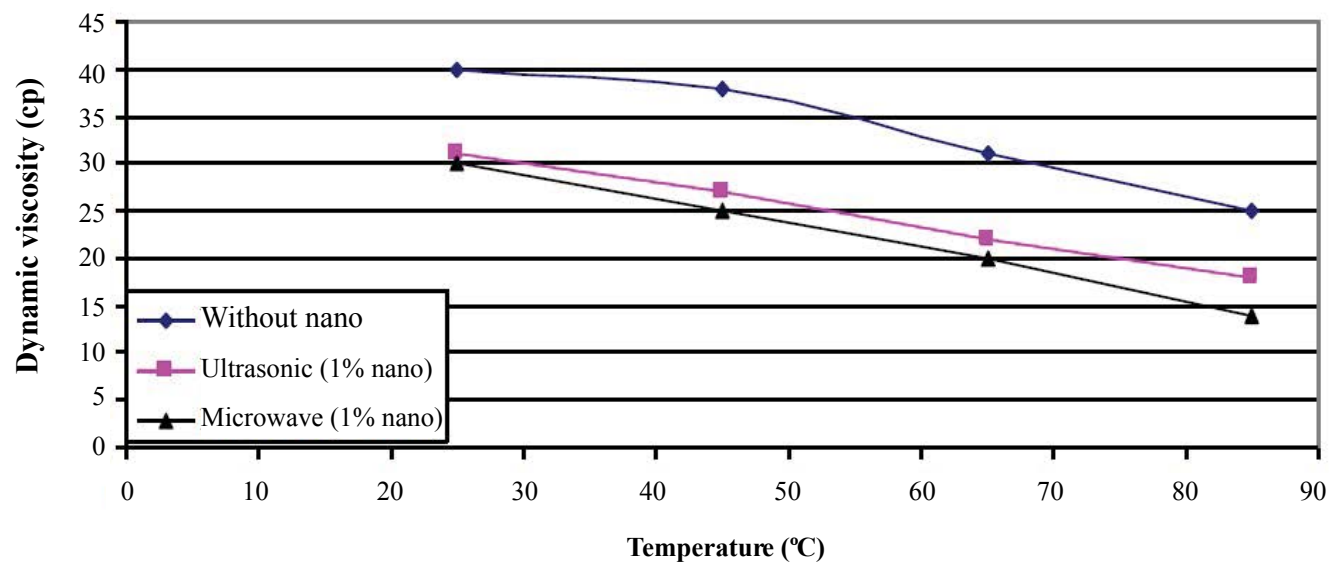

Figure 3: Dynamic viscosity versus temperature.

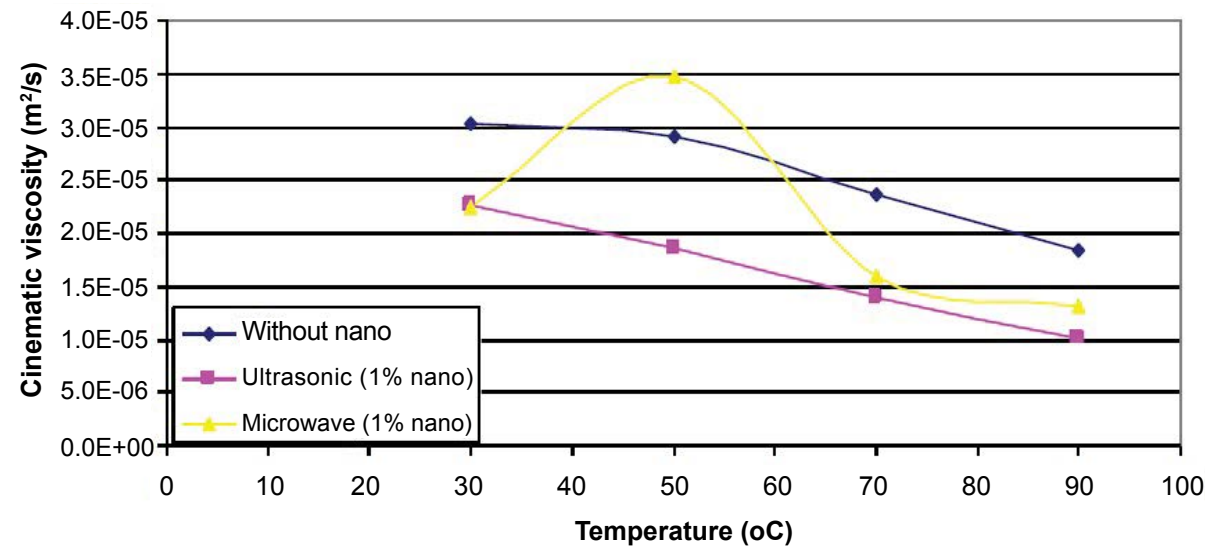

Figure 4: Cinematic viscosity versus temperature.

The higher amounts of yield point cause higher pressure loss during drilling. So, Nano drilling fluid which is made by microwave method shows the best amounts of yield point comparing with the other simple drilling fluid and ultrasonic drilling fluid.
Figure 7 shows the amounts of Reynolds number through the tube at $38^{\circ} \mathrm{C}$ operation temperature. Reynolds number includes the effect of some important properties which are average velocity and kinematic viscosity. The decrease trend of density by temperature 
Citation: Hosseini S, Farahbod F, Zargar G (2016) The Study of Effective of Added Aluminum Oxide Nano Particles to the Drilling Fluid: The Evaluation of Two Synthesis Methods. J Pet Environ Biotechnol 7: 283. doi:10.4172/2157-7463.1000283

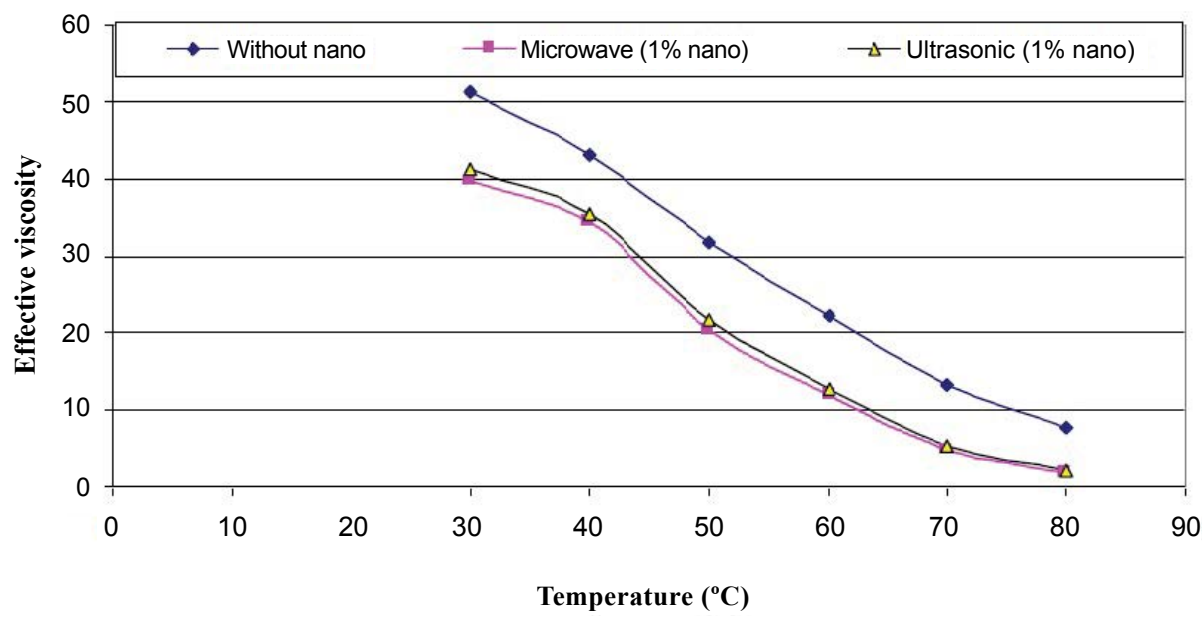

Figure 5: Effective viscosity versus temperature.

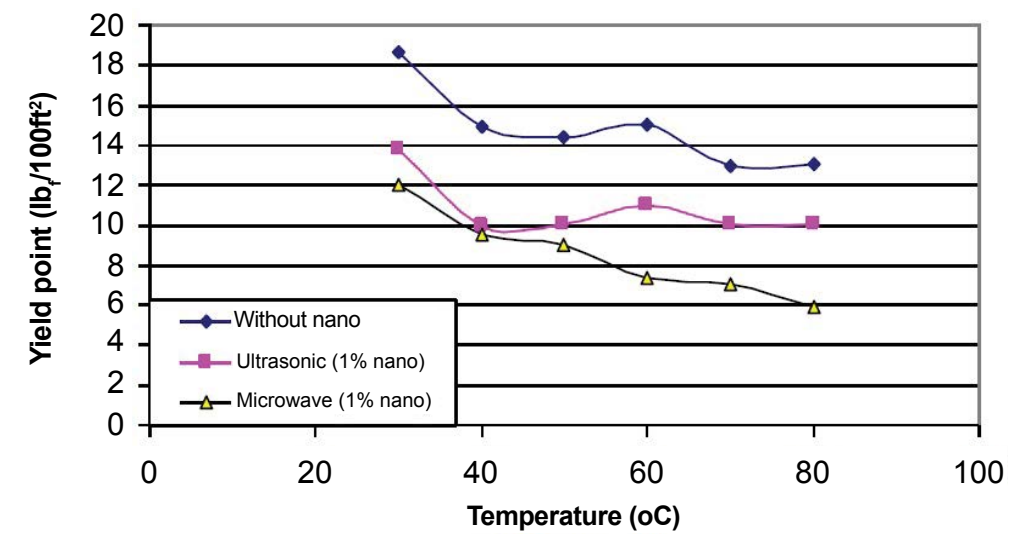

Figure 6: Yield point versus temperature.

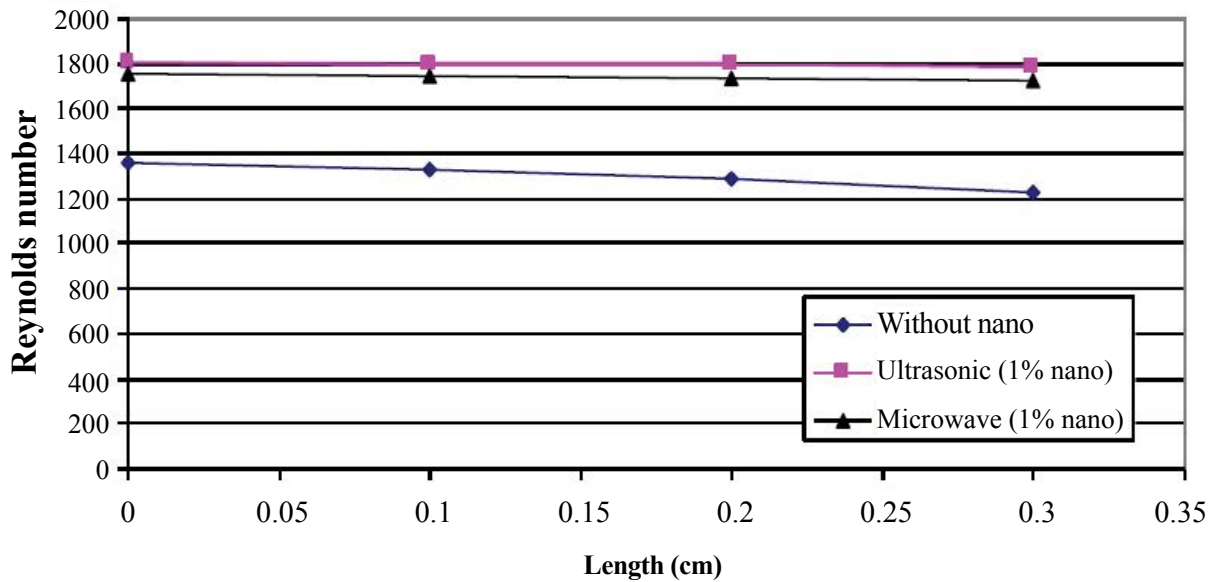

Figure 7: Reynolds number versus length.

is obviously depends on the higher amount of mean length of free path of molecules of drilling fluid at higher temperatures and the decrease in the amount of molecules in one unit of volume. So, the total difference in Reynolds number through $0.3 \mathrm{~m}$ is $135.3,18$ and 13 units for drilling fluid without Nano, ultrasonic and microwave drilling fluid respectively. So, ultrasonic nano drilling fluid seems to show more stable Reynolds number and flow regime through the tube. Figure 8 shows the values of friction factor through the tube length. Values of friction factor decreases through the length. According to the Figure 8 addition of Nano particles increases slightly the amount of 


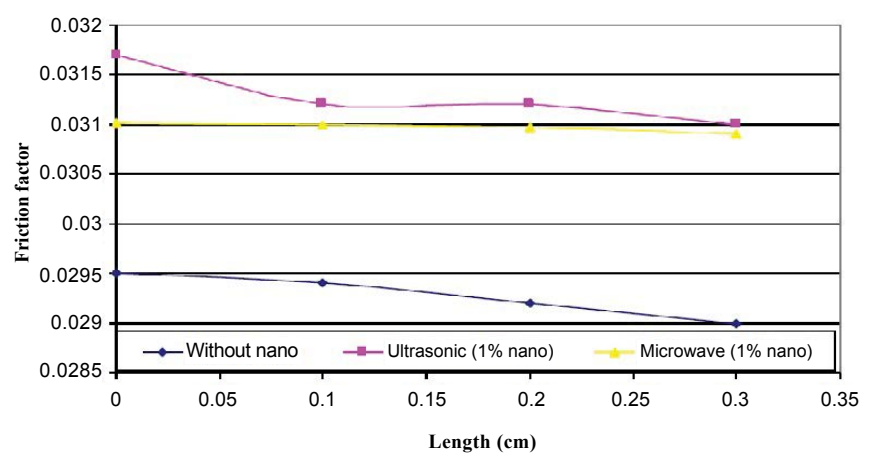

Figure 8: Friction factor versus length.

\begin{tabular}{|c|c|c|c|}
\hline Property & $\mathbf{R e}$ & $\mathbf{P r}$ & $\mathbf{P e}$ \\
\hline Ultrasonic Nano particle + drilling fluid & 1.38 & 0.222 & 1.07 \\
\hline Microwave Nano particle + drilling fluid & 1.34 & 0.223 & 1.04 \\
\hline
\end{tabular}

Table 2: The comparative results of basic parameters.

friction factor compares with simple drilling fluid. Due to the previous results of Reynolds number, the changes in amounts of this number affect obviously the amounts of friction factor. The decrease trend of this number through the length is obeyed by the amounts of friction factor. Also, addition of $1 \%$ Nano fluid prepared by ultrasonic and microwave increases the amount of friction factor respectively $6.84 \%$ and $5.8 \%$, averagely. This indicates the effect of preparation method of Nano particle on the amounts of friction factor besides the effect of Reynolds number and tube roughness on the amount of friction factor.

\section{Conclusions}

Drilling fluids play a major role in drilling purposes in oil and gas industries. In this study, thermal and rheological specifications of drilling fluid in ranges of temperature through the experimental tube section, resembling well condition, are obtained. Thermal specifications are also considered. The purpose of this experimental work is to find the answer of this question:" Does the method of preparation of $\mathrm{Nano}_{2} \mathrm{Al}_{2} \mathrm{O}_{3}$ particle affect the behavior of Nano drilling fluid?" So, experiments are handled to find the amounts of Prandtl and Stanton number, average velocity, dynamic viscosity, kinematic viscosity, yield point, Reynolds number and friction factor. The obtained results are valuable to predict the behavior of Nano drilling fluid in the determined conditions. However, this area needs more investigations. All experimental values of Nano drilling properties are compared with the amounts which are obtained for simple drilling fluid. Summary of the obtained results are mentioned. The addition of $1 \%$ Nano aluminum oxide into drilling fluid decreases values of plastic viscosity, effective viscosity, dynamic viscosity and yield point, generally. Ultrasonic Nano drilling fluid decreases value of effective viscosity about $40 \%$, dynamic viscosity about $30 \%$ and yield point about $27 \%$. Microwave Nano drilling fluid decreases value of effective viscosity about $44 \%$, dynamic viscosity about
$30 \%$ and yield point about $44 \%$. Addition of $1 \%$ Nano aluminum oxide which is prepared by ultrasonic method into drilling fluid increases the amount of friction factor $6.84 \%$ and velocity about $4.4 \%$, averagely. The addition of $1 \%$ Nano aluminum oxide which is prepared by microwave method into drilling fluid increases the amount of friction factor $5.8 \%$ and velocity about $3.7 \%$, averagely. Also, the comparative results are briefly presented in below chart as the fraction of value of Nano drilling fluid to the value related to the simple drilling fluid. The Table 2 shows the ratio of Reynolds, Prandtle and Peclet numbers.

Final conclusion introduces a new viewpoint about the effect of method of preparation of Nano aluminum oxide on the Nano drilling fluid. So, although the preparation method of Nano particle affects the behavior of Nano drilling fluid but this doesn't show any considerable effect. The difference between the results of ultrasonic drilling fluid and microwave Nano fluid can be bold under high temperature and high pressure conditions.

\section{References}

1. He J, Li J, Zhou Z, Zhang D (2012) Research on gas-cut while drilling volume calculation model during under balanced drilling. Information Computing and Applications 308: 701-708.

2. Yao $X$, Zhang $F$, Zhao $H$ (1989) Comprehensive determination of physical properties of rock formations; the quantitative analysis of the relation between porosity and depth (or permeability) for sandstone (or mudstone). Oil Geophys Prospect 24: 533-541.

3. Elkatatny S, Mahmoud MA, Nasr-El-Din HA (2012) Characterization of filter cake generated by water-based drilling fluids using CT scan, SPE Drill. Complet 27: 282-293.

4. Gao WJ, Lin HJ, Leung KT, Schraft $H$, Liao $B Q$ (2011) Structure of cake layer in a submerged anaerobic membrane bioreactor. J Membr Sci 374: 110-120.

5. Bageri BS, Al-Majed AA, Al-Mutairi SH, Ul-Hamid A, Sultan AS (2013) Evaluation of filter cake mineralogy in extended reach and maximum reservoir contact wells in sandstone reservoirs. SPE/IADC Drilling Conference and Exhibition.

6. Alexander L, Klug HP (1948) Basic aspects of X-Ray absorption in quantitative diffraction analysis of powder mixtures. Anal Chem 20: 886-889.

7. Ouhadi VR, Yong RN (2013) Impact of clay microstructure and mass absorption coefficient on the quantitative mineral identification by XRD analysis. Appl Clay Sci 23:141-148.

8. Bray HJ, Redfern SA, Clark SM (1998) The kinetics of dehydration in Camontmorillonite; and in situ X-ray diffraction study, Mineral Mag 62: 647-656.

9. Heller H, Keren R (2001) Rheology of Na-rich montmorillonite suspension as affected by electrolyte concentration and shear rate. Clay Clay Miner 49: 286291

10. Xuan Y, Jiang G, Li Y, Wang J, Geng H (2013) Inhibiting effect of dopamine adsorption and polymerization on hydrated swelling of montmorillonite. Colloids Surf A Physicochem Eng Asp 422: 50-60.

11. Luckham PF, Rossi S (1999) The colloidal and rheological properties of bentonite suspensions. Adv Colloid Interf Sci 82: 43-92.

12. Plank JP, Gossen FA (1991) Visualization of fluid-loss polymers in drilling-mud filter cakes. SPE Drill Eng. 6: 203-208.

13. Tung KL, Hu CC, Chuang CJ, Hwang KJ, Wu TY (2010) Effects of soft particle deformability and particle/pore size ratio on the blocking mechanism in deadend microfiltration. Chem Eng Technol 33: 1341-1348. 